\title{
Telomerase Activation to Reverse Immunosenescence in Elderly Patients With Acute Coronary Syndrome: Protocol for a Randomized Pilot Trial
}

Rebecca Maier ${ }^{1}$, MSc; Bilal Bawamia ${ }^{2}$, MBBS, MRCP; Karim Bennaceur ${ }^{3}, \mathrm{PhD}$; Sarah Dunn ${ }^{1}, \mathrm{MSc}$; Leanne Marsay ${ }^{1}$, $\mathrm{PhD}$; Roland Amoah ${ }^{3}$, MBBS; Adetayo Kasim ${ }^{4}$, PhD; Andrew Filby ${ }^{5}$, PhD; David Austin ${ }^{2}$, MD, FRCP; Helen Hancock $^{1}, \mathrm{PhD}$; Ioakim Spyridopoulos ${ }^{3}, \mathrm{MD}, \mathrm{FRCP}$

\footnotetext{
${ }^{1}$ Newcastle Clinical Trials Unit, Newcastle University, Newcastle Upon Tyne, United Kingdom

${ }^{2}$ James Cook University Hospital, Middlesbrough, United Kingdom

${ }^{3}$ Institute of Genetic Medicine, Newcastle University, Newcastle Upon Tyne, United Kingdom

${ }^{4}$ Wolfson Research Institute for Health and Wellbeing, Durham University, Durham, United Kingdom

${ }^{5}$ Flow Cytometry Core Facility, Newcastle University, Newcastle Upon Tyne, United Kingdom
}

\section{Corresponding Author:}

Ioakim Spyridopoulos, MD, FRCP

Institute of Genetic Medicine

Newcastle University

Central Parkway

Newcastle Upon Tyne,

United Kingdom

Phone: 441912418675

Email: Ioakim.spyridopoulos@newcastle.ac.uk

\begin{abstract}
Background: Inflammation plays a key role in the pathophysiology of coronary heart disease (CHD) and its acute manifestation, acute coronary syndrome (ACS). Aging is associated with a decline of the immune system, a process known as immunosenescence. This is characterized by an increase in highly proinflammatory $\mathrm{T}$ cells that are involved in CHD progression, plaque destabilization, and myocardial ischemia-reperfusion injury. Telomere dysfunction has been implicated in immunosenescence of T lymphocytes. Telomerase is the enzyme responsible for maintaining telomeres during cell divisions. It has a protective effect on cells under oxidative stress and helps regulate flow-mediated dilation in microvasculature.
\end{abstract}

Objective: The TACTIC (Telomerase ACTivator to reverse Immunosenescence in Acute Coronary Syndrome) trial will investigate whether a telomerase activator, TA-65MD, can reduce the proportion of senescent $\mathrm{T}$ cells in patients with ACS with confirmed CHD. It will also assess the effect of TA-65MD on decreasing telomere shortening, reducing oxidative stress, and improving endothelial function.

Methods: The study was designed as a single-center, randomized, double-blind, parallel-group, placebo-controlled phase II trial. Recruitment started in January 2019. A total of 90 patients, aged 65 years or older, with treated ACS who have had CHD confirmed by angiography will be enrolled. They will be randomized to one of two groups: TA-65MD oral therapy ( $8 \mathrm{mg}$ twice daily) or placebo taken for 12 months. The primary outcome is the effect on immunosenescence determined by a decrease in the proportion of CD8+ TEMRA (T effector memory cells re-expressing CD45RA [CD45 expressing exon A]) cells at 12 months. Secondary outcomes include leukocyte telomere length, endothelial function, cardiac function as measured by echocardiography and NT-proBNP ( $\mathrm{N}$-terminal fragment of the prohormone brain-type natriuretic peptide), systemic inflammation, oxidative stress, and telomerase activity.

Results: The study received National Health Service (NHS) ethics approval on August 9, 2018; Medicines and Healthcare products Regulatory Agency approval on October 19, 2018; and NHS Health Research Authority approval on October 22, 2018. The trial began recruiting participants in January 2019 and completed recruitment in March 2020; the trial is due to report results in 2021.

Conclusions: This pilot trial in older patients with CHD will explore outcomes not previously investigated outside in vitro or preclinical models. The robust design ensures that bias has been minimized. Should the results indicate reduced frequency of 
immunosenescent CD8+ T cells as well as improvements in telomere length and endothelial function, we will plan a larger, multicenter trial in patients to determine if TA-65MD is beneficial in the treatment of CHD in elderly patients.

Trial Registration: ISRCTN Registry ISRCTN16613292; http://www.isrctn.com/ISRCTN16613292 and European Union Drug Regulating Authorities Clinical Trials Database (EudraCT), European Union Clinical Trials Register 2017-002876-26; https://tinyurl.com/y4m2so8g

International Registered Report Identifier (IRRID): DERR1-10.2196/19456

(JMIR Res Protoc 2020;9(9):e19456) doi: 10.2196/19456

\section{KEYWORDS}

coronary heart disease; acute coronary syndrome; immunosenescence; telomerase activator

\section{Introduction}

\section{Background}

Inflammation plays a key part in the pathophysiology of coronary heart disease (CHD) and its acute manifestation - acute coronary syndrome (ACS) — from atheroma formation to plaque rupture [1]. Despite contemporary treatment, recurrent adverse events (AEs) post-ACS remain common, especially in the elderly [2]. Aging is associated with a decline of the immune system, a process known as immunosenescence [3], leading to an increased burden of disease. Targeting interleukin 1 (IL-1 $\beta$ ), the principal cytokine of innate immunity, in patients with previous myocardial infarction (MI) has been shown to reduce subsequent adverse cardiovascular outcomes [4]. Furthermore, the contribution of the adaptive immune system to the complex inflammatory response evoked during ACS has been demonstrated extensively in experimental and clinical studies [5]. In particular, highly proinflammatory senescent $\mathrm{T}$ cells are thought to be key players in plaque destabilization [6] and myocardial ischemia-reperfusion injury [7].

Telomere dysfunction has been implicated in immunosenescence of T cells $[3,8]$. Telomeres are DNA caps that protect the ends of chromosomal DNA. They are widely regarded as the internal biological clock of a living organism and shorten by a few base pairs with every cell division. This process can be slowed down by activation of telomerase, which is responsible for producing and maintaining telomeres. Shorter lymphocyte telomeres are associated with development of CHD as well as increased cardiovascular risk and mortality independent of conventional vascular risk factors [9-12]. Alleles associated with shorter telomere length (TL) were also associated with an increased risk of CHD, suggesting a causal relationship [13].

The TACTIC (Telomerase ACTivator to reverse Immunosenescence in Acute Coronary Syndrome) trial was designed to test whether a telomerase activator can reduce the proportion of senescent $\mathrm{T}$ cells in patients following ACS. There is accumulating evidence that telomerase, through its telomerase reverse transcriptase (TERT) catalytic subunit, contributes to cell physiology independently of its ability to elongate telomeres. We and our collaborators have demonstrated the effect of oxidative stress on telomerase as well as a telomere-independent protective effect of telomerase in cells under oxidative stress $[14,15]$. Telomerase activity (TA) has also been shown to regulate endothelial flow-mediated dilation (FMD) [16].
The small molecule cycloastragenol (CAG), isolated from the roots of the herb astragalus, is the only available telomerase activator in humans. TA-65MD is a purified and encapsulated form of CAG with increased bioavailability (T.A. Sciences). We have also shown that TA-65MD induces telomerase and proliferation in CD4 T lymphocytes in a TERT-dependent way [17]. In a randomized controlled trial investigating cytomegalovirus (CMV)-positive healthy subjects aged 53-87 years old, subjects taking $8 \mathrm{mg}$ of TA-65MD daily increased TL over the 12-month period, whereas subjects in the placebo group significantly lost TL [18].

\section{Trial Rationale}

The evidence indicates that telomerase deficiency in atherosclerosis leads to accelerated immunosenescence with telomere shortening in peripheral blood leukocytes, increased oxidative stress and inflammation, and impaired microvascular endothelial function, all of which contribute to CHD progression. We hypothesize that activating telomerase with TA-65MD will lead to reduced immunosenescence, decreased telomere shortening, and improved endothelial function in patients with CHD. The null hypothesis is that there will be no difference in immunosenescence between the two groups following 12 months of treatment with TA-65MD or placebo. The choice of active treatment versus placebo is appropriate in this population where no telomerase activator is currently used as part of usual care. All patients will receive usual care alongside the trial.

\section{Objectives}

\section{Primary Objective}

We aim to assess the effect of $8 \mathrm{mg}$ of oral TA-65MD given twice daily for 12 months on immunosenescence in older patients following ACS.

\section{Secondary Objectives}

The secondary objectives of this trial are as follows:

1. To investigate the effect of 1-year TA-65MD treatment on leukocyte TL.

2. To investigate the effect of 1-year TA-65MD treatment on microvascular endothelial function.

3. To investigate the effect of 1-year TA-65MD treatment on systemic inflammation and heart failure, reflected by expression of $\mathrm{N}$-terminal fragment of the prohormone brain-type natriuretic peptide (NT-proBNP) and high - sensitivity $\mathrm{C}$ - reactive protein (hsCRP). 
4. To investigate the effect of 1-year TA-65MD treatment on measures of cardiac function as measured by echocardiography.

5. To investigate the effect of TA-65MD treatment on TA and oxidative stress.

6. To investigate the effect of TA-65MD treatment on clinical events—all-cause death, stroke, or MI—in patients after 1 year.

7. To characterize the AE profile of TA-65MD.

8. To quantify adherence to study drugs.

9. To investigate the impact of seropositivity to CMV at baseline on trial outcomes.

\section{Methods}

\section{Trial Design}

This is a single-center, randomized, double-blind, parallel-group, placebo-controlled phase II trial comparing TA-65MD with placebo in 90 participants with CHD who have had ACS in the 6 months prior to consent. A total of 90 patients will be randomized to either the TA-65MD group $(n=45)$ or the placebo group ( $\mathrm{n}=45)$; TA-65MD and placebo will be taken by these groups, respectively, twice daily for 12 months. The schedule of this trial is shown in Table 1. The trial will run according the International Conference on Harmonisation (ICH)-Good Clinical Practice (GCP) and in accordance with relevant UK legislation and the trial protocol. This trial was registered at the International Standard Randomized Controlled Trial Number (ISRCTN) registry (16613292) and at the European Union Drug Regulating Authorities Clinical Trials Database (EudraCT), European Union Clinical Trials Register (2017-002876-26). 
Table 1. Trial schedule of assessments and interventions.

\begin{tabular}{|c|c|c|c|c|c|c|c|}
\hline \multirow[t]{2}{*}{ Schedule items } & \multicolumn{7}{|c|}{ Time of assessments and interventions } \\
\hline & Baseline $^{\mathrm{a}}$ & Day 1 & $\begin{array}{l}1 \text { month } \\
\text { (wks 3-5) }\end{array}$ & $\begin{array}{l}3 \text { months } \\
\text { (wks 11-15) }\end{array}$ & $\begin{array}{l}6 \text { months } \\
\text { (wks 24-28) }\end{array}$ & $\begin{array}{l}9 \text { months } \\
\text { (wks 37-41) }\end{array}$ & $\begin{array}{l}12 \text { months } \\
\text { (wks 50-54) }\end{array}$ \\
\hline \multicolumn{8}{|l|}{ Enrollment } \\
\hline Eligibility screen & $\mathrm{X}$ & & & & & & \\
\hline Informed consent & $\mathrm{X}$ & & & & & & \\
\hline \multicolumn{8}{|l|}{ Assessments } \\
\hline Blood pressure & $\mathrm{X}$ & & $\mathrm{X}$ & $\mathrm{X}$ & $\mathrm{X}$ & $\mathrm{X}$ & $\mathrm{X}$ \\
\hline Capillary glucose & $\mathrm{X}$ & & $\mathrm{X}$ & $\mathrm{X}$ & $\mathrm{X}$ & $\mathrm{X}$ & $\mathrm{X}$ \\
\hline Physical assessment of height and weight & $\mathrm{X}$ & & & & & & \\
\hline $\begin{array}{l}\text { Venous sample }(5 \mathrm{~mL}) \text { cytomegalovirus } \\
\operatorname{IgG}^{\text {b }}\end{array}$ & $\mathrm{X}$ & & & & & & \\
\hline $\begin{array}{l}\text { Venous sample ( } 4 \mathrm{~mL}) \text { CD8 TEMRA } \\
\text { immunosenescence (primary outcome) }\end{array}$ & $\mathrm{X}$ & & & & $\mathrm{X}$ & & $\mathrm{X}$ \\
\hline $\begin{array}{l}\text { Venous sample ( } 36 \mathrm{~mL} \text { ) CD } 8 \text { and } \mathrm{CD} 4 \\
\text { immunosenescence (secondary out- } \\
\text { comes), telomere length, and telomerase } \\
\text { activity }\end{array}$ & $\mathrm{X}$ & & & & $\mathrm{X}$ & & $\mathrm{X}$ \\
\hline $\begin{array}{l}\text { Venous sample }(4 \mathrm{~mL}) \text { oxidative stress, } \\
\text { future use }\end{array}$ & $\mathrm{X}$ & & & & $\mathrm{X}$ & & $\mathrm{X}$ \\
\hline $\begin{array}{l}\text { Venous sample }(5 \mathrm{~mL}) \text { future research } \\
\text { use-optional consent }\end{array}$ & $\mathrm{X}$ & & & & $\mathrm{X}$ & & $\mathrm{X}$ \\
\hline $\begin{array}{l}\text { Venous sample }(5 \mathrm{~mL}) \mathrm{hsCRP}^{\mathrm{e}} \text { and NT- } \\
\text { proBNP }^{\mathrm{f}}\end{array}$ & $\mathrm{X}$ & & & & $\mathrm{X}$ & & $\mathrm{X}$ \\
\hline $\begin{array}{l}\text { Endothelial function (EndoPAT [Periph- } \\
\text { eral Arterial Tone]) }\end{array}$ & $\mathrm{X}$ & & & & $\mathrm{X}$ & & $\mathrm{X}$ \\
\hline Echocardiography & $\mathrm{X}$ & & & & & & $\mathrm{X}$ \\
\hline \multicolumn{8}{|l|}{ Interventions } \\
\hline Randomization—stratified & $\mathrm{X}$ & & & & & & \\
\hline $\begin{array}{l}\text { Dispensing of investigational medicinal } \\
\text { product (IMP) }\end{array}$ & & $\mathrm{X}$ & $\mathrm{X}$ & $\mathrm{X}$ & $\mathrm{X}$ & $\mathrm{X}$ & $\mathrm{X}$ \\
\hline $\begin{array}{l}\text { Return of unused IMP and drug adher- } \\
\text { ence }\end{array}$ & & & $\mathrm{X}$ & $\mathrm{X}$ & $\mathrm{X}$ & $\mathrm{X}$ & $\mathrm{X}$ \\
\hline Adverse events evaluation & & & $\mathrm{X}$ & $\mathrm{X}$ & $\mathrm{X}$ & $\mathrm{X}$ & $\mathrm{X}$ \\
\hline
\end{tabular}

${ }^{\mathrm{a}}$ Baseline assessments are completed after written consent is obtained and are performed before randomization.

${ }^{\mathrm{b}} \mathrm{IgG}$ : immunoglobulin G.

${ }^{\mathrm{c}}$ TEMRA: T effector memory cells re-expressing CD45RA (CD45 expressing exon A).

${ }^{\mathrm{d}}$ Results from baseline immunosenescence sample are required for randomization.

ehsCRP: high - sensitivity $\mathrm{C}$ - reactive protein.

${ }^{f}$ NT-proBNP: N-terminal fragment of the prohormone brain-type natriuretic peptide.

\section{Primary Outcome}

The primary outcome is immunosenescence following 12 months of treatment with TA-65MD. Immunosenescence will be determined by flow cytometry and fluorescence-activated cell sorting (FACS) (see Figure 1); the proportion of terminally differentiated CD8+ effector memory cells (\% CD8+ TEMRA
[T effector memory cells re-expressing CD45RA (CD45 expressing exon A)]) will be calculated from the total number of peripheral blood CD8+ T lymphocytes. We have previously demonstrated the prognostic utility of CD8+ TEMRA as a measure for immunosenescence [19]. The mean difference between the intervention and control arms will be compared at 12 months. 
Figure 1. Example gating path for seven-color fluorescence-activated cell sorting (FACS) from ethylenediaminetetraacetic acid (EDTA) peripheral blood. AF700: Alexa Fluor 700; APC: allophycocyanin; BV421: Brillian Violet 421; CCR7: C-C chemokine receptor type 7; CD45RA: CD45 expressing exon A; CM: central memory; CX3CR1: C-X3-C motif chemokine receptor 1; EM: effector memory; FITC: fluorescein isothiocyanate; FSC: forward scatter; FSC-H: forward scatter-pulse height; PE: phycoerythrin; PE-Cy7: phycoerythrin and cyanine 7; SSC: side scatter; TEMRA: T effector memory cells re-expressing CD45RA; V500: violet 500 .
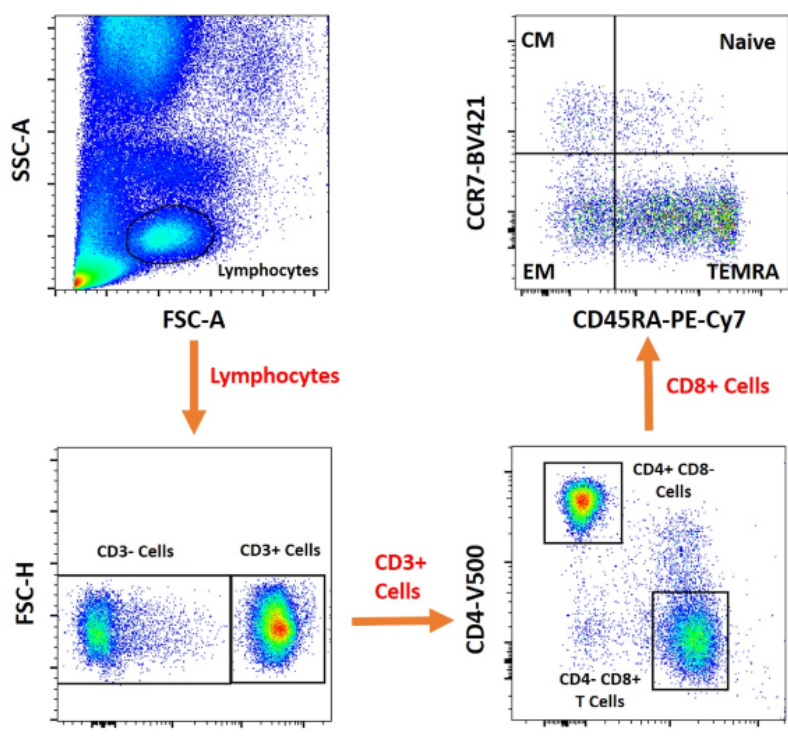

CD3-PE

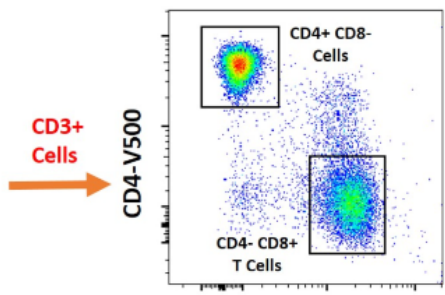

CD8-FITC

\section{Secondary Outcomes}

\section{CD8 T Cell Telomere Length}

TL will be determined from cryopreserved peripheral blood mononuclear cells (PBMCs) by flow cytometry-fluorescent in situ hybridization (flow-FISH) [9]. TL will be measured in total leukocytes and CD8+ T cells. CD8+ T cell TL is significantly reduced in patients with CHD and post-MI [9]. We expect TL in $\mathrm{CD} 8+\mathrm{T}$ cells to decrease less in patients treated with TA-65MD. TL will be measured in total leukocytes and in CD8+ $\mathrm{T}$ cells at baseline, 6 months, and 12 months.

\section{Microvascular Endothelial Function}

Microvascular endothelial function will be assessed by measuring FMD at baseline, 6 months, and 12 months. Using plethysmography at the fingertips of both hands, the EndoPAT (Peripheral Arterial Tone) system (Itamar Medical Ltd) will calculate an index of pulse wave amplitude after cuff occlusion to before occlusion of the test arm divided by the same ratio of the control arm, namely the reactive hyperemic index. FMD has been shown to be compromised in patients with CHD and microvascular dysfunction as a predictor of adverse clinical outcome [20].

\section{Systemic Inflammation}

Systemic inflammation will be assessed using the hsCRP, which is a downstream biomarker of inflammation associated with an increased risk of cardiovascular events [21].

\section{Cardiac Function}

Cardiac function will be assessed by NT-proBNP and transthoracic echocardiography at baseline and 12 months. Together, these measures will determine myocardial function, strain (NT-proBNP), and global longitudinal strain, reflecting

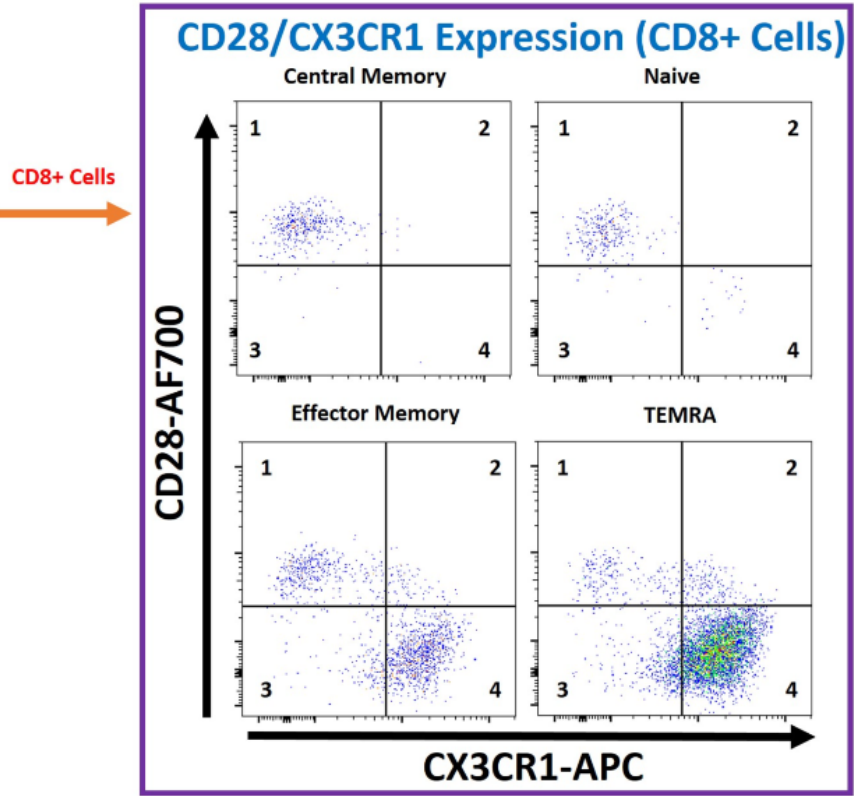

the pathophysiological targets of heart failure. Lack of telomerase and presence of shortened telomeres in cardiomyocytes from preclinical models (ie, mice) have been shown to be critical in the development of heart failure in that species [22]. Patients with chronic heart failure have shorter TL compared to age- and gender-matched controls with incremental attrition according to the presence and extent of coronary artery disease (CAD) [23].

\section{Telomerase Activity}

TA will be assessed by a modified telomeric repeat amplification protocol (TRAP) assay, using digital droplet polymerase chain reaction (PCR) $[24,25]$. This provides an indication of drug effect: TA-65MD is expected to increase TA in PBMCs.

\section{Oxidative Stress}

Oxidative stress will be measured with the thiobarbituric acid reactive substances (TBARS) colorimetric assay (Oxford Biomedical Research) from freshly collected and cryopreserved plasma. TBARS is an established assay to quantify lipid peroxides [26].

\section{Seropositivity to Cytomegalovirus}

The effect of CMV seropositivity at baseline will be correlated with study outcomes using an exploratory analysis. CMV is a highly prevalent human herpes virus with CMV seropositivity present in a large proportion of elderly patients. CMV-directed cells increase with age, constituting a large proportion of the total CD8+ $\mathrm{T}$ cell pool in elderly individuals [27]. $\mathrm{T}$ cell responses to CMV are restricted to a limited number of epitopes, resulting in progressive, prolonged oligoclonal expansion of $\mathrm{CMV}$-specific CD8+ $\mathrm{T}$ cells in a process known as memory inflation [28]. We have previously shown that individuals who are seropositive have a much higher proportion of CD8+ TEMRA cells and have a greater risk of heart attacks [7,29]. 


\section{Clinical Outcomes and Adverse Events}

Major clinical events will be measured for 12 months from the start of treatment. All-cause death, MI, and stroke will be presented as a composite outcome-major adverse cardiac and cerebrovascular events (MACCE) — and also reported separately. All AEs, including those considered related and unrelated to the intervention, will be recorded and reported from the time of randomization for 12 months or until a patient has completed all trial activities.

\section{Study Setting}

The trial aims to recruit 90 patients. All patients will be recruited, treated, and followed up at a single site: The James Cook University Hospital, Middlesbrough, UK. Blood samples

Textbox 1. Inclusion and exclusion criteria. will be analyzed at site laboratories and, where specialist equipment and expertise are required, will be transported to the Institute of Genetic Medicine, Newcastle University, UK, for analysis.

\section{Study Visits and Assessments}

Following baseline assessment and initiation of treatment-placebo or TA-65MD—patients in both groups will be followed up at 1 month, 3 months, 6 months, 9 months, and 12 months (see Table 1). At each visit, drug adherence will be assessed and the patient will be evaluated for AEs.

\section{Inclusion and Exclusion Criteria}

Textbox 1 lists the criteria informing the eligibility or exclusion of patients for the trial.

Inclusion criteria - patients will be eligible for the trial if they:

- $\quad$ Provide written informed consent

- Are male or female, aged 65 years or over, with an index presentation of an acute coronary syndrome (ACS)* within the previous 6 months

- Have successfully completed revascularization** or are being managed medically following ACS

- Have angiographic evidence of coronary heart disease: at least one major epicardial vessel stenosis $\geq 70 \%$

- $\quad$ Are recruited more than 24 hours after presentation with the index ACS event

*ACS defined as either a non-ST elevation myocardial infarction (NSTEMI) or ST elevation myocardial infarction (STEMI)

**Percutaneous coronary intervention or angioplasty, eligible the following day, or coronary artery bypass grafting, eligible 3 months following surgery

Exclusion criteria-patients will be excluded from the trial if they:

- Have any disorder associated with immunological dysfunction (ie, acute or chronic inflammatory or neoplastic coexisting disease, known positive serology for HIV, or hepatitis)

- $\quad$ Are clinically unstable (ie, hemodynamically unstable, cardiogenic shock, or unconscious)

- Have severe, uncontrolled hypertension (blood pressure [BP] >170/110 $\mathrm{mmHg}$ or ambulatory $\mathrm{BP}$ of $150 / 95 \mathrm{mmHg}$ )

- Have a severe comorbidity that has impact on outcome over the next 2 years

- $\quad$ Are taking immunosuppressants

- Have a known malignancy

- Currently use a nutritional supplement derived from the roots of the

Astragalus

species

- Have a previous known substance addiction

- Have insulin-dependent diabetes

- Are judged by the investigator that they should not participate in the study, for example, on the basis of previous serious psychiatric illness or are unlikely to comply with study procedures, restrictions, and requirements

- Have participated in any other interventional medicinal study in the past 6 months

\section{Trial Procedures}

\section{Screening, Recruitment, and Consent of Participants}

Potential participants will be identified by the clinical team following admission to hospital with ACS and having agreed to undergo coronary angiography or having already had an angiography that confirms CHD. Patients may also be identified following discharge. Potentially eligible participants will be invited to participate by a delegated member of the study team. The trial will be explained by the clinical research team and, after time for questions, written consent will be sought from the patient. Written informed consent will be obtained prior to any trial specific procedures and prior to randomization. There will be additional consent for storage of blood samples for up to 5 years for future use in ancillary studies. Patients have the right to withdraw from the trial at any time and without 
providing a reason. With the explicit consent of patients, general practitioners will be informed of their participation.

\section{Eligibility Assessment}

Following consent, the principal investigator or a subinvestigator on the delegation log will confirm the patient's eligibility. Patients who do not meet trial eligibility criteria prior to randomization will be considered a screen failure and withdrawn from the trial with no further data collected.

\section{Randomization}

Randomization will be performed using the Sealed Envelope Ltd system with a minimization scheme to ensure patients randomized to each group are comparable at baseline. The minimization scheme will account for (1) gender (male or female), (2) type of ACS (ST elevation myocardial infarction [STEMI] or non-ST elevation myocardial infarction [NSTEMI]), and (3) CD8+ TEMRA (high $>45 \%$ or low $\leq 45 \%$ ) at baseline.

Eligible patients will be randomized by delegated and trained members of the research team at each center using the 24-hour, central, secure, web-based randomization system with concealed allocation. Eligible patients will be randomized in a 1:1 ratio to receive TA-65MD (intervention under study) or placebo (control arm).

\section{Blinding}

Assignment to either the TA-65MD or placebo groups will be blinded to the patient, treating clinicians, and the clinical research team, including the pharmacy, research nurses, echocardiogram assessors, laboratory staff, and the chief investigator. Blinding will be maintained in the randomization system, the electronic case report forms (eCRFs), and on investigational medicinal product (IMP) labels. All members of the Newcastle Clinical Trial Unit (NCTU) and the statistics team will be blinded, with the exception of the trial data manager to enable reporting to the independent data monitoring committee as appropriate. The IMP will be labeled using a unique identification code, which will be linked to the study randomization system. TA-65MD and its matched placebo will be identical and presented in the same packaging to ensure blinding of the IMP.

\section{Unblinding}

Unblinding should not occur except in the case of medical emergencies, where the appropriate management of the patient requires the knowledge of the randomization allocation. To avoid unnecessary unblinding, it will be assumed that the patient is on active treatment within the trial. The Sealed Envelope Ltd online web-based randomization service will be used for emergency unblinding. The primary trial analysis will be performed prior to unblinding. All patients will be informed of which arm they were assigned to, once analysis of the trial data is complete.

\section{Study Intervention}

\section{Intervention Under Study: TA-65MD}

TA-65MD is marketed as a dietary supplement. The active ingredient of TA-65MD is $1.8 \%$ CAG, isolated from roots of the Astragalus species. The active ingredient has been identified in an empirical screen of traditional Chinese medicine plant extracts and compounds. TA-65MD is an activator of telomerase, an enzyme whose actions protect the ends of chromosomes from shortening associated with repeated cellular replication. Patients allocated to the intervention will be given $8 \mathrm{mg}$ of TA-65MD twice daily.

\section{Control Arm: Placebo}

The matched placebo has been manufactured to ensure that it is consistent with TA-65MD in appearance, taste and smell, labeling, packaging, and batch number. Patients allocated to the placebo group will be given this twice daily.

\section{Safety Data}

\section{Overview}

An independent expert panel has determined TA-65MD to be Generally Recognized As Safe (GRAS) for use in a medical food under the provisions of the Federal Food, Drug, and Cosmetic Act, administered by the US Food and Drug Administration. T.A. Sciences, Inc, provided extensive animal and human clinical data to support the status of GRAS. The safety of TA-65MD has been assessed in an observational study of 114 adults over the course of 1 year [30]. At doses up to 50 mg per day there were no AEs reported for TA-65MD. Safety was also assessed in a randomized, placebo-controlled study involving 117 adult volunteers over the course of 1 year, with no toxicities detected in the liver, kidneys, and metabolic functions as assessed by biochemical markers [29]. An anticipated risk for the use of TA-65MD relates to its ability to activate telomerase. This is the subject of scientific conjecture in consideration of its relationship to cancer [31,32]. An in vitro assay testing the telomerase-activating potency of TA-65 (ie, CAG not in capsules) in Medical Research Council cell strain-5 (MRC-5) fibroblasts suggested there was dose-related TA (Sierra Sciences Labs). While telomerase activation has been observed, TA-65MD does not increase the lifespan of cells. In fact, the preliminary observation of a controlled in vivo cancer study using $5 \mathrm{~mL} / \mathrm{kg}$ of TA-65 (ie, CAG not in capsules) or sham drug administered by oral gavage for up to 40 days in mice xenografted with four different human tumors-lung (H460), colon (HT29), breast (MDA-MB-435), and prostate (PC3) — suggests a trend toward tumor growth retardation in two cancer types; as well, there was no statistically significant adverse effects on body weight or tumor size for any of the cell lines nor on the growth rate of the tumors (internal T.A. Sciences document, 2008). Given that the population under study in the TACTIC trial are elderly with ACS, and that there were no data on the impact of the drug on the outcomes or population, we chose to conduct the trial using a conservative dose of $8 \mathrm{mg}$ twice daily.

\section{Known Side Effects}

TA-65MD may interfere with medications that suppress the immune system and may also affect blood sugar and blood pressure. In an observational study, two subjects self-reported an "anxious" feeling shortly after voluntarily increasing their daily consumption of TA-65MD to $100 \mathrm{mg}$ /day-a self-imposed choice without physician approval at a consumption level two times above the intended dose for this observational study; the 
feelings resolved in both subjects when daily consumption was returned to $50 \mathrm{mg} /$ day.

\section{Administration and Adherence}

Participants may begin taking the IMP immediately following the completion of all baseline assessments, confirmation of eligibility, and randomization. A dose of $8 \mathrm{mg}$ of TA-65MD (T.A. Sciences) or matched placebo will be taken as $1 \times 8-\mathrm{mg}$ capsule twice daily (ie, morning and evening). Participants will take the allocated IMP until the end of follow-up at 12 months. Patients will be prescribed IMP following randomization and at $1,3,6$, and 9 months following the start of the intervention. Returned capsules at each visit will be used to calculate the adherence for each participant. Concomitant medications will also be reviewed and documented at each visit.

\section{Withdrawal of Participants}

Participants will be made aware of their right to withdraw from the trial at any time for any reason and without giving a reason. Participants will be withdrawn from the trial by the clinical team for any of the following reasons:

1. Intercurrent illness means the participant is no longer able to complete study procedures.

2. The patient suffers unacceptable side effects caused by the study drug.

3. Suspected unexpected serious adverse reactions occur.

The investigator can withdraw participants in the event of any reason that would compromise participant safety or the validity of the results. Data and blood samples collected up to the point of withdrawal will be kept and used in the analysis of the trial unless the participant explicitly requests for these to be removed.

\section{Pharmacovigilance}

All AEs will be recorded in the participants' medical notes and on the eCRFs. AEs will be recorded from the day of randomization until the last visit or until withdrawal, with the exception of those considered related to the IMP, which will be followed until resolution, a stable outcome, or death. All AEs are assessed for severity, causality, expectedness, and seriousness by an investigator; all are reviewed by the Independent Data Monitoring and Ethics Committee (IDMEC). In accordance with current legislation, AEs will, where necessary, undergo expedited reporting to the sponsor and to the Medicines and Healthcare products Regulatory Agency (MHRA) within the required timelines.

\section{Statistical Considerations}

\section{Overview}

A pragmatic decision was taken to recruit and analyze data on 90 patients: 45 in each group. This sample size is the minimum conventional threshold for making parameter estimates in pilot studies [33]. The parameter estimates in this trial will be used to inform a large, multicenter clinical trial.

\section{Data Management}

Study data are recorded in each patient's medical notes before being recorded onto eCRFs, which are developed and managed by the NCTU. The eCRF has been built using the Red Pill system supplied by Sealed Envelope Ltd. Data entered onto the eCRF must be consistent with the information in the medical notes. Patients are identified using a unique study ID; all data passed to the NCTU will have patient identifiers removed, with the exception of date of birth, gender, ethnicity, and study ID. Data cleaning is provided by staff within the NCTU.

\section{Statistical Analysis}

Primary analysis will follow intention-to-treat principles with patient data analyzed according to randomization and irrespective of intervention received; other analysis groups, such as per-protocol groups, may be considered subsequently. Every effort will be made to retain and include all patients who are part of the trial.

Data will be summarized by study group. Mean or median will summarize continuous variables, whereas number and percentage will be used to summarize categorical variables. A general linear model will be used to analyze the primary outcome considering all covariates used in the randomization scheme. Similar methods will be used to analyze all continuous secondary outcomes. Data of other types will be analyzed using generalized linear models with appropriate distributions.

The numbers of MACCE after 12 months will be compared between arms by the use of standardized rates (eg, by consideration of the number of events per patient month in each arm). Impact of missing data will be explored by tabulating the proportion of missing data in each arm. A full statistical analysis plan will be developed for the outcome measures and agreed upon with the IDMEC and the chief investigator prior to any analysis being undertaken.

\section{Trial Governance}

The trial is sponsored by South Tees Hospitals National Health Service (NHS) Foundation Trust and funded by T.A. Sciences, Inc, New York, USA. The trial is being run in collaboration with the NCTU at Newcastle University. The sponsor and funder were not involved in the trial design. The sponsor has delegated the trial design; collection, management, analysis, and interpretation of data; report writing; and publications to the chief investigator and coinvestigators. The trial is overseen by the Trial Steering Committee, which meets every 6 months and includes an independent chair and two other independent members, one of whom is a patient. In addition, the trial includes the IDMEC, which meets every 6 months and oversees all ethical and safety issues in accordance with a study-specific DAMOCLES (Data Monitoring Committees: Lessons, Ethics, and Statistics) charter. All members are independent of the study team, although the trial manager, chief investigator, and some other members of the Trial Management Group attend the open sessions in order to inform the committee about the trial progress. The IDMEC makes recommendations to the Trial Steering Committee. The day-to-day supervision of the trial will be the responsibility of the Trial Management Group, who report to the Trial Steering Committee.

\section{Dissemination and Publications Policy}

The trial will be published in peer-reviewed journals following the end of the trial, and the data will be presented at national 
and international meetings. We do not intend to use professional writers. Results of the trial will also be reported to the funder, sponsor, and the Research Ethics Committee within one year after the end of the trial. Trial participants will be informed about the trial results and their treatment allocation at the end of the trial, including a lay summary. The datasets analyzed during this study are available from the corresponding author on reasonable request.

\section{Results}

The study received NHS ethics approval on August 9, 2018; MHRA approval on October 19, 2018; and NHS Health Research Authority approval on October 22, 2018. The trial began recruiting participants in January 2019 and completed recruitment in March 2020; the trial is due to report results in 2021.

During the COVID-19 pandemic, all patients will have their visits carried out remotely. Primary and secondary outcome measures that are not able to be carried out remotely will occur later than planned, on-site, as soon as it is safe for the patients to do so and when laboratories are able to process and analyze trial samples. Measures of blood pressure and blood glucose will be undertaken by patients who have not yet attended the site for their 6-month visit. Portable blood pressure monitors and blood glucose monitors will be sent to those patients to be used to record their results at home when required as per the schedule of events for the duration of the pandemic. Some patients may require continuation of the IMP beyond 12 months to enable them to attend the hospital for their final trial visit assessments. The 6-month and 12-month visits will occur as soon as it is safe for this group of patients to attend the hospital and when the trial laboratories are able to accommodate processing and analysis of trial samples.

\section{Discussion}

$\mathrm{ACS}$, the acute manifestation of atherosclerosis, is a leading cause of mortality and morbidity. Age is an independent risk factor for adverse cardiovascular outcomes after ACS, and this is likely related to upregulation of the inflammatory response that occurs with aging. Improvements in cardiovascular outcomes over the last two decades have been realized mainly in younger patients [34]. There remains an unmet need for novel therapeutic approaches in older patients following ACS $[35,36]$.

The CANTOS (Canakinumab Anti-Inflammatory Thrombosis Outcomes Study) trial has provided strong evidence for the critical role of inflammation in atherosclerosis by showing that canakinumab - a human monoclonal anti-IL- $1 \beta$ antibody-led to a reduction in major cardiovascular events independent of lipid-level lowering [4]. Canakinumab was associated with a higher incidence of nonfatal infection, potentially limiting its use in older patients with CHD.

TA-65MD, the only available human telomerase activator, has been shown to increase TL in human subjects. We hypothesize that maintaining and/or lengthening telomeres can reduce $\mathrm{T}$ cell immunosenescence, thus reducing their proinflammatory effects. Telomerase has also been shown to have telomere-independent properties in vitro, namely, a protective effect in cells under oxidative stress and an ability to regulate FMD in the human microvasculature.

The proposed pilot trial in older patients with CHD will provide findings not previously investigated outside in vitro or preclinical models, which will substantially enhance our understanding of telomerase activators in this population and their potential for benefit. The double-blind, randomized, placebo-controlled design of the TACTIC trial will provide the gold standard for evaluating signs of efficacy of TA-65MD. Should the results indicate reduced frequency of immunosenescent CD8+ T cells and improvements in TL as well as endothelial function, we will aim to follow up with a larger, multicenter efficacy trial in patients to determine if TA-65MD is beneficial in the treatment of CHD.

\section{Acknowledgments}

This trial would not be possible without the commitment and enthusiasm of clinicians, nurses (notably, Laura Thompson and Ben Ward), professionals, and patients within the Cardiology Department at The James Cook University Hospital, Middlesbrough, UK. Our thanks go to them and to the NCTU team. The trial is sponsored by South Tees Hospitals NHS Foundation Trust and funded by T.A. Sciences, Inc, New York, USA.

\section{Authors' Contributions}

IS conceived the idea for the study. IS, RM, HH, and AK co-designed the trial and secured funding from T.A. Sciences; together with DA, LM, and SD, they wrote the full TACTIC trial protocol. DA is the principal investigator at the recruiting center and leads recruitment and treatment of patients. BB is the clinical research fellow, recruits patients, undertakes assessments, and supports IS and DA. RM and HH provide methodological input and oversee NCTU activity. AK leads the statistical aspects and analysis. SD manages the trial, sets up the center, and performs monitoring. KB undertakes the assessment of blood samples at Newcastle University, including for the primary outcome. RA developed and validated the telomerase and TL assays needed for the trial and continues to advise in this capacity. AF is the core facility manager and has developed the validation of the FACS protocol (ie, primary outcome); he will continue to provide a quality assurance role in relation to the analysis of samples at Newcastle University. This paper was drafted from the approved version of the protocol; all authors commented and amended drafts of the paper and approved the final version. All authors read and approved the final manuscript. 


\section{Conflicts of Interest}

DA has received consultancy fees from Novartis, speaker fees from Astra Zeneca, and proctoring and speaker fees from Abbott Vascular. IS received an investigator-initiated trial grant from T.A. Sciences.

\section{References}

1. Libby P, Tabas I, Fredman G, Fisher EA. Inflammation and its resolution as determinants of acute coronary syndromes. Circ Res 2014 Jun 06;114(12):1867-1879 [FREE Full text] [doi: 10.1161/CIRCRESAHA.114.302699] [Medline: 24902971]

2. Brieger D, Fox KAA, Fitzgerald G, Eagle KA, Budaj A, Avezum A, Global Registry of Acute Coronary Events Investigators. Predicting freedom from clinical events in non-ST-elevation acute coronary syndromes: The Global Registry of Acute Coronary Events. Heart 2009 Jun;95(11):888-894. [doi: 10.1136/hrt.2008.153387] [Medline: 19246481]

3. Wang JC, Bennett M. Aging and atherosclerosis: Mechanisms, functional consequences, and potential therapeutics for cellular senescence. Circ Res 2012 Jul 06;111(2):245-259. [doi: 10.1161/CIRCRESAHA.111.261388] [Medline: 22773427]

4. Ridker PM, Everett BM, Thuren T, MacFadyen JG, Chang WH, Ballantyne C, CANTOS Trial Group. Antiinflammatory therapy with canakinumab for atherosclerotic disease. N Engl J Med 2017 Sep 21;377(12):1119-1131. [doi: 10.1056/NEJMoa1707914] [Medline: 28845751]

5. Hansson GK, Hermansson A. The immune system in atherosclerosis. Nat Immunol 2011 Mar;12(3):204-212. [doi: 10.1038/ni.2001] [Medline: 21321594]

6. $\quad$ Liuzzo G, Goronzy JJ, Yang H, Kopecky SL, Holmes DR, Frye RL, et al. Monoclonal T-cell proliferation and plaque instability in acute coronary syndromes. Circulation 2000 Jun 27;101(25):2883-2888. [doi: 10.1161/01.cir.101.25.2883] [Medline: 10869258 ]

7. Hoffmann J, Shmeleva EV, Boag SE, Fiser K, Bagnall A, Murali S, et al. Myocardial ischemia and reperfusion leads to transient CD8 immune deficiency and accelerated immunosenescence in CMV-seropositive patients. Circ Res 2015 Jan 02;116(1):87-98 [FREE Full text] [doi: 10.1161/CIRCRESAHA.116.304393] [Medline: 25385851]

8. Spyridopoulos I, Hoffmann J, Aicher A, Brümmendorf TH, Doerr HW, Zeiher AM, et al. Accelerated telomere shortening in leukocyte subpopulations of patients with coronary heart disease: Role of cytomegalovirus seropositivity. Circulation 2009 Oct 06;120(14):1364-1372. [doi: 10.1161/CIRCULATIONAHA.109.854299] [Medline: 19770396]

9. Haycock PC, Heydon EE, Kaptoge S, Butterworth AS, Thompson A, Willeit P. Leucocyte telomere length and risk of cardiovascular disease: Systematic review and meta-analysis. BMJ 2014 Jul 08;349:g4227 [FREE Full text] [doi: 10.1136/bmj.g4227] [Medline: 25006006]

10. Farzaneh-Far R, Cawthon RM, Na B, Browner WS, Schiller NB, Whooley MA. Prognostic value of leukocyte telomere length in patients with stable coronary artery disease: Data from the Heart and Soul Study. Arterioscler Thromb Vasc Biol 2008 Jul;28(7):1379-1384 [FREE Full text] [doi: 10.1161/ATVBAHA.108.167049] [Medline: 18467646]

11. Brouilette S, Singh RK, Thompson JR, Goodall AH, Samani NJ. White cell telomere length and risk of premature myocardial infarction. Arterioscler Thromb Vasc Biol 2003 May 01;23(5):842-846. [doi: 10.1161/01.ATV.00000667426.96344.32] [Medline: 12649083]

12. Samani NJ, Boultby R, Butler R, Thompson JR, Goodall AH. Telomere shortening in atherosclerosis. Lancet 2001 Aug 11;358(9280):472-473. [doi: 10.1016/S0140-6736(01)05633-1] [Medline: 11513915]

13. Scheller Madrid A, Rode L, Nordestgaard B, Bojesen S. Short telomere length and ischemic heart disease: Observational and genetic studies in 290022 individuals. Clin Chem 2016 Aug;62(8):1140-1149. [doi: 10.1373/clinchem.2016.258566] [Medline: 27259814]

14. Haendeler J, Hoffmann J, Diehl JF, Vasa M, Spyridopoulos I, Zeiher AM, et al. Antioxidants inhibit nuclear export of telomerase reverse transcriptase and delay replicative senescence of endothelial cells. Circ Res 2004 Apr 02;94(6):768-775. [doi: 10.1161/01.RES.0000121104.05977.F3] [Medline: 14963003]

15. Ahmed S, Passos JF, Birket MJ, Beckmann T, Brings S, Peters H, et al. Telomerase does not counteract telomere shortening but protects mitochondrial function under oxidative stress. J Cell Sci 2008 Apr 01;121(Pt 7):1046-1053 [FREE Full text]

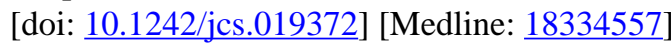

16. Beyer AM, Freed JK, Durand MJ, Riedel M, Ait-Aissa K, Green P, et al. Critical role for telomerase in the mechanism of flow-mediated dilation in the human microcirculation. Circ Res 2016 Mar 04;118(5):856-866 [FREE Full text] [doi: 10.1161/CIRCRESAHA.115.307918] [Medline: 26699654]

17. Richardson GD, Sage A, Bennaceur K, Al Zhrany N, Coelho-Lima J, Dookun E, et al. Telomerase mediates lymphocyte proliferation but not the atherosclerosis-suppressive potential of regulatory T-cells. Arterioscler Thromb Vasc Biol 2018 Jun;38(6):1283-1296 [FREE Full text] [doi: 10.1161/ATVBAHA.117.309940] [Medline: 29599138]

18. Salvador L, Singaravelu G, Harley CB, Flom P, Suram A, Raffaele JM. A natural product telomerase activator lengthens telomeres in humans: A randomized, double blind, and placebo controlled study. Rejuvenation Res 2016 Dec;19(6):478-484 [FREE Full text] [doi: 10.1089/rej.2015.1793] [Medline: 26950204]

19. Martin-Ruiz C, Hoffmann J, Shmeleva E, Zglinicki TV, Richardson G, Draganova L, et al. CMV-independent increase in CD27-CD28+ CD8+ EMRA T cells is inversely related to mortality in octogenarians. NPJ Aging Mech Dis 2020;6:3 [FREE Full text] [doi: 10.1038/s41514-019-0041-y] [Medline: $\underline{31993214]}$ 
20. Matsuzawa Y, Lerman A. Endothelial dysfunction and coronary artery disease: Assessment, prognosis, and treatment. Coron Artery Dis 2014 Dec;25(8):713-724 [FREE Full text] [doi: 10.1097/MCA.0000000000000178] [Medline: 25365643]

21. Emerging Risk Factors Collaboration, Kaptoge S, Di Angelantonio E, Lowe G, Pepys MB, Thompson SG, et al. C-reactive protein concentration and risk of coronary heart disease, stroke, and mortality: An individual participant meta-analysis. Lancet 2010 Jan 09;375(9709):132-140 [FREE Full text] [doi: 10.1016/S0140-6736(09)61717-7] [Medline: 20031199]

22. Wong LS, Oeseburg H, de Boer RA, van Gilst WH, van Veldhuisen DJ, van der Harst P. Telomere biology in cardiovascular disease: The TERC-/- mouse as a model for heart failure and ageing. Cardiovasc Res 2009 Feb 01;81(2):244-252. [doi: 10.1093/cvr/cvn337] [Medline: 19047341]

23. van der Harst P, van der Steege G, de Boer RA, Voors AA, Hall AS, Mulder MJ, MERIT-HF Study Group. Telomere length of circulating leukocytes is decreased in patients with chronic heart failure. J Am Coll Cardiol 2007 Apr 03;49(13):1459-1464. [doi: 10.1016/j.jacc.2007.01.027] [Medline: 17397675]

24. Bennaceur K, Atwill M, Al Zhrany N, Hoffmann J, Keavney B, Breault D, et al. Atorvastatin induces T cell proliferation by a telomerase reverse transcriptase (TERT) mediated mechanism. Atherosclerosis 2014 Oct;236(2):312-320. [doi: 10.1016/j.atherosclerosis.2014.07.020] [Medline: 25127175]

25. Ludlow AT, Robin JD, Sayed M, Litterst CM, Shelton DN, Shay JW, et al. Quantitative telomerase enzyme activity determination using droplet digital PCR with single cell resolution. Nucleic Acids Res 2014 Jul;42(13):e104. [doi: 10.1093/nar/gku439] [Medline: 24861623]

26. Armstrong D, Browne R. The analysis of free radicals, lipid peroxides, antioxidant enzymes and compounds related to oxidative stress as applied to the clinical chemistry laboratory. Adv Exp Med Biol 1994;366:43-58. [doi: 10.1007/978-1-4615-1833-4 4] [Medline: 7771281]

27. Khan N, Shariff N, Cobbold M, Bruton R, Ainsworth JA, Sinclair AJ, et al. Cytomegalovirus seropositivity drives the CD8 T cell repertoire toward greater clonality in healthy elderly individuals. J Immunol 2002 Aug 15;169(4):1984-1992. [doi: 10.4049/jimmunol.169.4.1984] [Medline: 12165524]

28. Kim J, Kim A, Shin E. Cytomegalovirus infection and memory T cell inflation. Immune Netw 2015 Aug;15(4):186-190 [FREE Full text] [doi: 10.4110/in.2015.15.4.186] [Medline: 26330804]

29. Spyridopoulos I, Martin-Ruiz C, Hilkens C, Yadegarfar ME, Isaacs J, Jagger C, et al. CMV seropositivity and T-cell senescence predict increased cardiovascular mortality in octogenarians: results from the Newcastle 85+ study. Aging Cell 2016 Apr;15(2):389-392 [FREE Full text] [doi: 10.1111/acel.12430] [Medline: 26696322]

30. Harley CB, Liu W, Blasco M, Vera E, Andrews WH, Briggs LA, et al. A natural product telomerase activator as part of a health maintenance program. Rejuvenation Res 2011 Feb;14(1):45-56 [FREE Full text] [doi: 10.1089/rej.2010.1085] [Medline: 20822369]

31. Harley CB. Telomerase is not an oncogene. Oncogene 2002 Jan 21;21(4):494-502 [FREE Full text] [doi: 10.1038/sj.onc.1205076] [Medline: 11850774]

32. Kim S, Kaminker P, Campisi J. Telomeres, aging and cancer: In search of a happy ending. Oncogene 2002 Jan 21;21(4):503-511 [FREE Full text] [doi: 10.1038/sj.onc.1205077] [Medline: 11850775]

33. Teare MD, Dimairo M, Shephard N, Hayman A, Whitehead A, Walters SJ. Sample size requirements to estimate key design parameters from external pilot randomised controlled trials: A simulation study. Trials 2014 Jul 03;15:264 [FREE Full text] [doi: 10.1186/1745-6215-15-264] [Medline: 24993581]

34. Alexander KP, Peterson ED. Treatment of non-ST-elevation acute coronary syndrome in the elderly: Current practice and future opportunities. Am J Geriatr Cardiol 2006;15(1):42-49. [doi: 10.1111/j.1076-7460.2006.04642.x] [Medline: 16415646]

35. Roffi M, Patrono C, Collet J, Mueller C, Valgimigli M, Andreotti F, ESC Scientific Document Group. 2015 ESC Guidelines for the management of acute coronary syndromes in patients presenting without persistent ST-segment elevation: Task Force for the Management of Acute Coronary Syndromes in Patients Presenting without Persistent ST-Segment Elevation of the European Society of Cardiology (ESC). Eur Heart J 2016 Jan 14;37(3):267-315. [doi: 10.1093/eurheartj/ehv320] [Medline: 26320110]

36. Amsterdam E, Wenger N, Brindis R, Casey D, Ganiats T, Holmes D, ACC/AHA Task Force Members, Society for Cardiovascular Angiography and Interventions and the Society of Thoracic Surgeons. 2014 AHA/ACC guideline for the management of patients with non-ST-elevation acute coronary syndromes: Executive summary: A report of the American College of Cardiology/American Heart Association Task Force on Practice Guidelines. Circulation 2014 Dec 23;130(25):2354-2394. [doi: 10.1161/CIR.0000000000000133] [Medline: 25249586]

\section{Abbreviations}

ACS: acute coronary syndrome

AE: adverse event

CAD: coronary artery disease

CAG: cycloastragenol

CANTOS: Canakinumab Anti-Inflammatory Thrombosis Outcomes Study

CHD: coronary heart disease 
CMV: cytomegalovirus

DAMOCLES: Data Monitoring Committees: Lessons, Ethics, and Statistics

eCRF: electronic case report form

EudraCT: European Union Drug Regulating Authorities Clinical Trials Database

FACS: fluorescence-activated cell sorting

flow-FISH: flow cytometry-fluorescent in situ hybridization

FMD: flow-mediated dilation

GCP: Good Clinical Practice

GRAS: Generally Recognized As Safe

hsCRP: high - sensitivity $\mathrm{C}$ - reactive protein

ICH: International Conference on Harmonisation

IDMEC: Independent Data Monitoring and Ethics Committee

IL-1: interleukin 1

IMP: investigational medicinal product

ISRCTN: International Standard Randomized Controlled Trial Number

MACCE: major adverse cardiac and cerebrovascular events

MHRA: Medicines and Healthcare products Regulatory Agency

MI: myocardial infarction

MRC-5: Medical Research Council cell strain-5

NCTU: Newcastle Clinical Trial Unit

NHS: National Health Service

NSTEMI: non-ST elevation myocardial infarction

NT-proBNP: N-terminal fragment of the prohormone brain-type natriuretic peptide

PAT: Peripheral Arterial Tone (in EndoPAT)

PBMC: peripheral blood mononuclear cell

PCR: polymerase chain reaction

STEMI: ST elevation myocardial infarction

TA: telomerase activity

TACTIC: Telomerase ACTivator to reverse Immunosenescence in Acute Coronary Syndrome

TBARS: thiobarbituric acid reactive substances

TEMRA: T effector memory cells re-expressing CD45RA (CD45 expressing exon A)

TERT: telomerase reverse transcriptase

TL: telomere length

TRAP: telomeric repeat amplification protocol

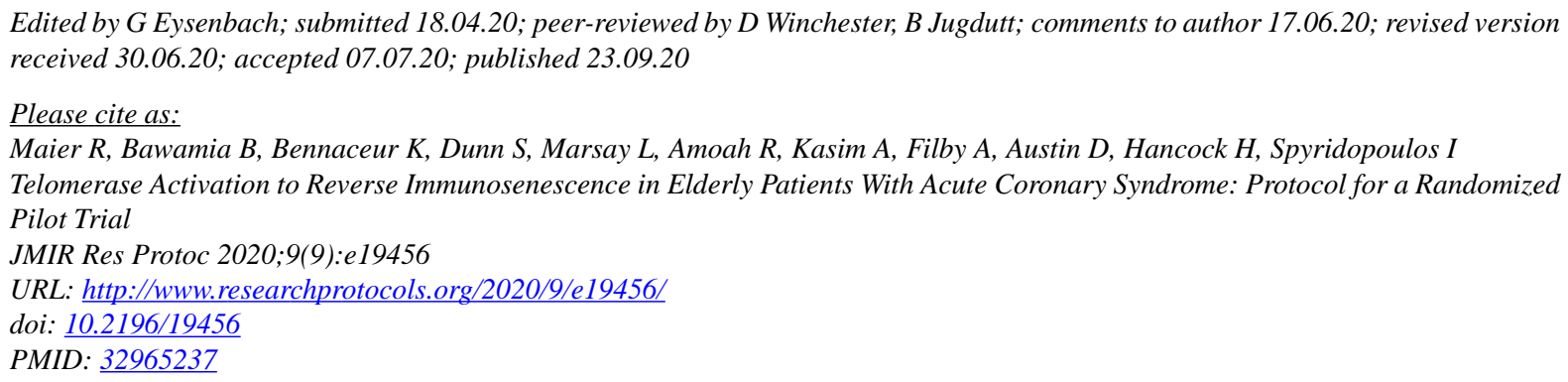

ORebecca Maier, Bilal Bawamia, Karim Bennaceur, Sarah Dunn, Leanne Marsay, Roland Amoah, Adetayo Kasim, Andrew Filby, David Austin, Helen Hancock, Ioakim Spyridopoulos. Originally published in JMIR Research Protocols (http://www.researchprotocols.org), 23.09.2020. This is an open-access article distributed under the terms of the Creative Commons Attribution License (https://creativecommons.org/licenses/by/4.0/), which permits unrestricted use, distribution, and reproduction in any medium, provided the original work, first published in JMIR Research Protocols, is properly cited. The complete bibliographic information, a link to the original publication on $\mathrm{http} / / / \mathrm{www}$.researchprotocols.org, as well as this copyright and license information must be included. 